\title{
Cinsel İstismar ve Çocukluk Çağı Gebelikler: 111 Olguda Analitik Değerlendirme
}

\section{Sexual Abuse and Childhood Pregnancies: An Analytical Evaluation of 111 Case}

\author{
Berna Aydın ${ }^{1}$, Ahmet Turla ${ }^{1}$, Cihad Dündar ${ }^{2}$

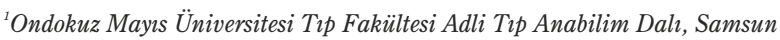 \\ ${ }^{2}$ Ondokuz Mayıs Üniversitesi Tıp Fakültesi Halk Sağlı̆̆ Anabilim Dalı, Samsun \\ *Bu çalışmanın verileri 3-6 Haziran 2015 tarihinde yapılacak olan XII. Adli Bilimler Kongresinde poster bildiri olarak sunulmak üzere kabul edilmiştir.
}

\section{Özet}

Amaç: Bu çalışmada cinsel istismar sonucu gebe kalan çocukların uğradığı istismara ve gebeliklerine ilişkin özellikler ile ruhsal etkilenmenin boyutunun araştırılması amaçlanmıştır.

Gereç ve Yöntem: Çalışmada 6 yıllık sürede Ondokuz Mayıs Üniversitesi Tıp Fakültesi Adli Tıp Anabilim Dalına muayene edilerek rapor düzenlenmesi için gönderilen cinsel istismar sonucu gebe kalmış 18 yaş altındaki 111 çocuğa ait hasta dosyaları incelenmiştir.

Bulgular: Çocuklarda ilk gebelik yaș ortalaması 14,51,3 (11-17) yıldır. Kurbanların \%41,4'ünde tehdit, hile, kandırma veya zorlama ile istismarın gerçekleștiği ve \%68,5'inde istismarın tekrarladığ 1 , çocukların \%13,5'inin aile üyelerinden birinin istismarı sonucu gebe kaldığ 1 , gebe kalan çocukların yaklaşık yarısının doğum yaptığı, doğan çocukların ise yaklaşık yarısının annesinden ayrı kurum bakımında olduğu, 3 çocuğun da evlat edindirildiği belirlenmiştir. İstismar sonucu gebe kalan çocukların yarısında yaşadıkları olay nedeniyle ruhsal patoloji geliştiği; tehdit/kandırma, tekrarlayan istismar ve ensest varlığının ruhsal patoloji için risk faktörü olduğu saptanmıştır.

Sonuç: İstismar mağduru gebe kalan çocuklar sadece beden ve ruh sağlığı açısından değil, eğitimi bırakmak, ekonomik bağımlı olmak gibi sosyal alanlarda da uzun süreli ve kalıcı etkilere maruz kalmaktadır. Bu nedenle, akut dönemde başvuran cinsel istismar mağdurlarında acil kontrasepsiyon uygulanarak bu olumsuz etkilerin önlenebileceği dikkate alınmalıdır. Akut dönemden sonra başvuran mağdurlarda ise gebelik olup olmadığı erken dönemde araştırılmalı, varolan gebelikler istem halinde uygun koşullarda sonlandırılmalıdır. Ayrıca bu çocuklar ruhsal patolojilerin rehabilitasyonu için de izleme alınmalıdır.

Anahtar Kelimeler: Çocuk cinsel istismarı, Gebelik, Ruhsal patoloji.

\section{Giriş}

Cinsel suçlar, çok yönlü olumsuz sonuçları açısından, belki de toplumda en ciddi biçimde ele alınması gerekli suç türlerindendir (1). Cinsel istismar/saldırı tüm yaş gruplarındaki kadın ve erkekleri etkilemekle birlikte, kadınlar ve çocukların daha fazla risk altında olduğu bilinmektedir (1-3).

Çocukluk çağı travmaları içinde de çocuk cinsel istismarı yinelenebilirliği ve çocuğa genellikle en yakınları tarafından yapilıyor olması nedeniyle tanımlanması ve tedavi edilmesi en zor olan travma şeklidir (4).

Cinsel istismar kurbanı çocuklarda davranış problemleri,

Sorumlu Yazar: Doç.Dr. Berna AYDIN

Ondokuz Mayss Üniversitesi Tip Fakültesi

Adli Tip Anabilim Dalı - Atakum / Samsun

E-posta:drbernaaydin@yahoo.com

baydin@omu.edu.tr

Tel: 0362 3121919-3044

Geliș: 20.05.2015

Düzeltme: 26.06.2015

\section{Abstract}

Objective: The purpose of this study was to investigate characteristics of abuse suffered by children exposed to sexual abuse resulting in pregnancy, the features of those pregnancies, and the scale of the psychological impact involved.

Materials and Methods: Patient records for 111 children under the age of 18 who became pregnant as a result of sexual abuse and were referred for reports and examination to the Ondokuz Mayıs University Mdical Faculty Forensic Medicine Department over a 6-year period were investigated.

Results: Mean age at first pregnancy was $14.51 .3(11-17)$ years. Of the victims, $41.4 \%$ reported that sexual abuse took place due to threats, deception or compulsion, $68.5 \%$ reported abuse was repeated, $13.5 \%$ fell pregnant as a result of abuse by a member of the family, approximately half of the pregnant children gave birth, approximately half of the babies were placed in care away from the mother and three were adopted. Psychological pathologies due to their experiences developed in half the pregnant victims of abuse, and threats/deception, repeated abuse and presence of incest were identified as risk factors for psychological pathology.

Conclusion: Victims of abuse who fall pregnant are exposed to longterm and permanent effects, not just in terms of physical and mental health, but also in the social sphere, such as economic dependence. It should therefore be remembered that these adverse effects in victims of sexual abuse presenting in the acute period can be overcome through the administration of emergency contraception. In victims presenting after the acute period, however, the presence or otherwise of pregnancy must be investigated early, and pregnancies must be terminated under appropriate conditions if so desired. In addition, these children must be placed under monitoring for the rehabilitations of psychological pathologie.

Keywords: Child sexual abuse, Pregnancy, Psychological pathology.

sosyal izolasyon, uygunsuz cinsel davranışlar, intihar düşüncesi veya davranışı, anksiyete bozuklukları, depresyon ve travma sonrası stres bozukluğu (TSSB) en sik bildirilen sorunlardır (5-8). Özellikle cinsel istismar, kurbanların \%3550 'sinde görülen TSSB için önemli bir risk faktörü olarak tanımlanmıştır (9). Ayrıca istismara uğrayan çocuk ve ergenlerde yaşamın ilerleyen dönemlerinde birçok ruhsal bozukluğun ortaya çıktığı da bildirilmektedir $(10,11)$.

Eğer cinsel istismar sonucu bir de gebelik meydana gelmiş ise adli, ahlaki ve etik sorunlar kadar anne ve çocuğunun sağlığı ile ilgili yeni sorunlar da ortaya çıkmaktadır. Adölesan gebeliklerinde anne ölümü, hastalık, sakatlık, erken doğum, güvensiz düşük ve komplikasyonları, cinsel yolla bulaşan hastalıklar ve infanta ait sağlık risklerinde artış görülmektedir (12).

Bu nedenle çocukların cinsel istismarı sonrasındaki adli ve tıbbi süreçte, ruhsal değerlendirmenin yanısıra acil 
kontrasepsiyon, terminasyon açısından gebeliğin erken dönemde tespit edilmesi, varolan gebeliğin devamına ilişkin kararın bir an önce verilmesi ve istem halinde uygun koşullarda sonlandırılması, devamı halinde de sosyal ve medikal desteğin sağlanması önemlidir.

Bu çalışmada cinsel istismar sonucu gebe kalan çocukların uğradığı istismara ve gebeliklerine ilişkin özellikler ile istismara bağlı olarak gelişen ruhsal etkilenmenin boyutunun araştırılması amaçlanmıştır.

\section{Gereç ve Yöntem}

Adli makamlar tarafından cinsel istismar nedeniyle muayene edilerek haklarında rapor düzenlenmesi istemiyle Ondokuz Mayıs Üniversitesi Tıp Fakültesi Adli Tıp Anabilim Dalına gönderilen olgulardan, 01.01.2009-31.01.2015 tarihleri arasında muayene edilen cinsel istismar sonucu gebe kalmış 18 yaş altındaki toplam 111 olgu çalışmaya alınmış ve olgulara ait hasta dosyaları retrospektif olarak incelenmiştir.

Adli Tıp Anabilim Dalında genel beden muayeneleri yapılmış bu çocuklar ve varsa ebeveynleri ile Çocuk ve Ergen Psikiyatrisi Anabilim Dalında psikiyatrik görüşmeler yapılmış, gereken olgularda diğer bölümlerden de konsültasyon istenmiştir.

Çocukların sosyodemografik bilgileri, yaşadığı istismar ve gebelik ile ilgili bilgiler ve muayene bulguları kaydedilmiştir.

Hasta dosyalarından elde edilen veriler SPSS istatistik programı (Version 15.0, SPSS Inc., Chicago, Illinois) ile değerlendirilmiştir. Gruplar arasındaki karşılaştırmalarda kikare testi, cinsel istismar sonrası ruhsal patoloji gelişmesini etkileyen faktörlerin belirlenmesi amacıyla binary lojistik regresyon analizi (Enter method) kullanılmıştır. İstatistiksel anlamlılık düzeyi olarak p <0,05 kabul edilmiştir.

\section{Bulgular}

İstismar kurbanı çocukların ilk gebelik yaş ortalaması 14,51,3 (11-17) yıldır. Çocukların sadece \%50,5’inin (56 çocuk) gebe kaldığında öğrenci olduğu, bu çocukların da \%58,9'unun (33 çocuk) olay nedeniyle okulu terk ettiği öğrenilmiştir.

Olguların tümünde istismarı gerçekleştirenin çocuğun daha önceden tanıdığı birisi olduğu ve 15 olguda $(\% 13,5)$ ensest bulunduğu belirlenmiştir. Kurbanların \%41,4'ünde tehdit, hile, kandırma veya zorlama ile istismarın gerçekleştiği ve \%68,5’inde istismarın tekrarladığ1 görülmüştür (Tablo 1).
Tablo 1. Çocukların maruz kaldığı cinsel istismar ile ilgili veriler.

\begin{tabular}{|c|c|c|}
\hline Istismara Ilișkin Özellikler & Sayı & $\%$ \\
\hline \multicolumn{3}{|l|}{ Mağdur istismarca yakınlığ } \\
\hline Erkek arkadas & 42 & 37,9 \\
\hline Dini nikahla evlendirildiōi kocası & 21 & 18,9 \\
\hline Diḡer akrabalar & 19 & 17,1 \\
\hline Aile tiyeleri & 15 & 13,5 \\
\hline Komsu & 6 & 5,4 \\
\hline Arkadas & 5 & 4,5 \\
\hline Aile tiyelerinin arkadaș & 3 & 2.7 \\
\hline \multicolumn{3}{|l|}{ Tehdit, hile, kandırma veya zorlama } \\
\hline Var & 46 & 41.4 \\
\hline Yok & 65 & 58,6 \\
\hline \multicolumn{3}{|l|}{ Tekrarlayan istismar } \\
\hline Var & 76 & 68,5 \\
\hline Yok & 35 & 31.5 \\
\hline
\end{tabular}

Olguların \%44,2'si kendisi şüphelenip test yaptığında gebe olduğunu anladığını, \%35,1’i aileden birinin ve \% 3,6'sı öğretmeninin şüphelenmesi sonucu, \%17,1’i de başka bir nedenle götürüldüğü sağlık kuruluşunda gebe olduğunun ortaya çıktığını belirtmiştir.

Çocukların \%36,9'unun muayene sırasında gebeliği devam etmekte olup $53(\% 47,8)$ çocuğun doğum yapmış olduğu belirlenmiştir. 53 çocuğun 5’i ölü doğum, 2'si erken doğum yaptığını, erken doğum yapanlardan birisi 7 aylık, özürlü ve ikiz bebek doğurduğunu belirtmiştir. 4 çocuk düşük yapmıştır. 13 çocuğun ise gebeliği ortalama 13,86,8 (2,5-27) haftalık iken istem üzerine sonlandırılmıştır ( 7 çocuğun $\leq 10$ haftalık, 8 çocuğun $>10-20$ haftalık, 1 çocuğun 22 ve 1 çocuğun da 27 haftalık gebe iken). Bu çocuklarda gebeliğin tespit edilmesi ile sonlandırılması arasındaki süre ortalama 2,72,6 (0-8) haftadır.

Canlı doğan 49 çocuğun \%44,9'unun annesinden ayrı çocuk yuvasında kurum bakımında olduğu, \%12,2'sinin annesi ile birlikte kadın sığınma evinde bulunduğu, \%6,1'inin de evlat edindirildiği öğrenilmiştir.

Çocukların gebelik ile ilgili verileri Tablo 2'de gösterilmiştir.

Tablo 2. Çocukların gebelik ile ilgili verileri.

\begin{tabular}{|c|c|c|}
\hline Gebelik ve Cocuḡa İliskin Özellikler & Sayn & $\%$ \\
\hline \multicolumn{3}{|l|}{ Gebelix̧in ortaya cakas spekli } \\
\hline Kendisi suphelenip test yapems & 49 & 44,2 \\
\hline Aile süphekenip bekime götilirmus & 39 & 35,1 \\
\hline $\begin{array}{l}\text { Baska bir nedenle gittigi/gibtiruldago } \\
\text { hekim muayenesi sonucunda }\end{array}$ & 19 & 17,1 \\
\hline $\begin{array}{l}\text { Og̃retmen süphelenip hekime gitmesini } \\
\text { önermis }\end{array}$ & 4 & 3,6 \\
\hline \multicolumn{3}{|l|}{ Gebeligin sonucu } \\
\hline Canlı Doḡum & 48 & 43,2 \\
\hline Halen gebe & 41 & 36,9 \\
\hline Sonlandirnimı & 13 & 11.8 \\
\hline Olit Doğum & 5 & 4.5 \\
\hline Diisuk & 4 & 3,6 \\
\hline \multicolumn{3}{|l|}{ Doğan cocữun durumu (n:49) } \\
\hline Annesinden ayn yuvida & 22 & 44,9 \\
\hline Annesinin yanmda exde & 18 & 36,8 \\
\hline Annesi ile birlikke kaden sığmma evinde & 6 & 12,2 \\
\hline Evlathk werilmis & 3 & 6,1 \\
\hline
\end{tabular}


İstismar sonucu gebe kalan çocukların \%50,4 (56 çocuk)'ünde yaşadıkları olay nedeniyle ruhsal patoloji geliştiği, 24 çocuğun depresif bozukluk, 5 çocuğun TSSB ve 27 çocuğun da depresif bozukluk ve TSSB tanısı aldığı belirlenmiştir.
Çocukların 10'unda hafif derecede, birinde ise orta derecede zekâ geriliği bulunmaktadır. Ruhsal patoloji varlığının istismara ilişkin özelliklere göre dağılımı Tablo 3'de gösterilmiştir.

Tablo 3. Ruhsal patoloji varlığının istismara ilişkin özelliklere göre dă̆ılımı.

\begin{tabular}{|c|c|c|c|c|c|c|}
\hline \multirow{3}{*}{ Ístismara fllişkin Özellikler } & \multicolumn{4}{|c|}{ Ruhsal patoloji } & \multirow[b]{3}{*}{$\mathrm{x}^{2}$} & \multirow[b]{3}{*}{$\mathrm{p}$} \\
\hline & \multicolumn{2}{|c|}{ Var } & \multicolumn{2}{|c|}{ Yok } & & \\
\hline & Sayz & $\%$ & Say1 & $\%$ & & \\
\hline \multicolumn{7}{|l|}{ Magdur istismarcı yakınlyğ } \\
\hline Aile üyeleri & 13 & 86,7 & 2 & 13,3 & \multirow{4}{*}{29,51} & \multirow{4}{*}{0,000} \\
\hline Diger akrabalar & 14 & 73.7 & 5 & 26,3 & & \\
\hline Dini nikahla eviendinildigi kocası & 1 & 4,8 & 20 & 95,2 & & \\
\hline Komsu/erkek arkadas/dixer tanıdik & 28 & 50,0 & 28 & 50,0 & & \\
\hline \multicolumn{7}{|l|}{ Tehdit, hile, kandırma veya zorlama } \\
\hline Var & 45 & 97.8 & 1 & 2,2 & \multirow{2}{*}{70,53} & \multirow{2}{*}{0,000} \\
\hline Yok & 11 & 16,9 & 54 & 83,1 & & \\
\hline \multicolumn{7}{|l|}{ Tekrarlayan istismar } \\
\hline Var & 30) & 39,5 & 46 & 60,5 & \multirow{2}{*}{11,61} & \multirow{2}{*}{0.001} \\
\hline Yok & 26 & 74,3 & 9 & 25,7 & & \\
\hline \multicolumn{7}{|l|}{ Gebelik durumu } \\
\hline Halen gebe & 12 & 29.3 & 29 & 70,7 & \multirow{4}{*}{17,82} & \multirow{4}{*}{0,0000} \\
\hline Dox̌um & 29 & 54.7 & 24 & 45,3 & & \\
\hline Dusuk & 3 & 75,0 & 1 & 25,0 & & \\
\hline Sonlanderilms & 12 & 92,3 & 1 & 7.7 & & \\
\hline
\end{tabular}

Tablo 4'de sunulduğu gibi, ruhsal patoloji gelişiminde risk faktörü olduğu düşünülen etkenler için yapılan lojistik regresyon analizinde tehdit/kandırma ve tekrarlayan istismar varlığının istatistiksel olarak anlamlı bir şekilde yüksek risk faktörü olduğu; mağdur-istismarcı ilişkisi kategorik olarak değerlendirildiğinde ise ensest varlı̆̆ının ruhsal patoloji riskini yaklaşık on kat arttırdığı saptanmıştır.

Tablo 4. Ruhsal patoloji oluşumunda risk faktörü olduğu düşünülen bazı değişkenler için lojistik regresyon analizi sonuçları.

\begin{tabular}{|c|c|c|c|}
\hline Risk Faktörü için değişkenler & $\begin{array}{l}\text { Odds } \\
\text { Ratio }\end{array}$ & Güven Aralığ & p \\
\hline Tehdit / kandırma & 349,403 & $29,89-4084,3$ & 0,000 \\
\hline Tekrarlayan istismar & 6,979 & $1,310-37,171$ & 0,023 \\
\hline Halen gebe olma & 4,530 & $0,920-22,292$ & 0,063 \\
\hline Istismanc (Dini nikahla evlendirildiḡi ksocası) & & & 0,163 \\
\hline Istismarc (aile üyeleri) & 10,484 & $1,973 \cdot 55,869$ & 0,035 \\
\hline Istismarcı (akraba) & 2,6655 & $0,167-4,383$ & 0,308 \\
\hline Istismarc (komsu/erkek arkadas/diğer tamudik) & 3,682 & $0,096-8,946$ & 0,265 \\
\hline Constant & 0,025 & $0,007-0,0854$ & 0,000 \\
\hline
\end{tabular}

\section{Tartişma}

Çocukluk döneminde maruz kalınan her türlü örselenme, yarattığ1 ruhsal patoloji kadar çocuğun yaşam kalitesini de olumsuz etkilemektedir. Özellikle cinsel istismar k1z çocuklarında daha da derin ve erişkinliğe uzanan psikopatolojilere neden olmaktadır $(13,14)$. Bu çalışmada

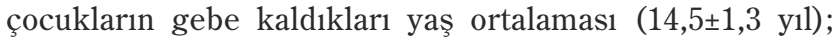
evlendirildiğinde 15 yaşını, değerlendirme sırasında 18 yaşını doldurmamış 48 olguyu inceleyen Soylu ve ark.nın çalışmasındaki gebelik yaşılla uyum göstermektedir (15). Yani her iki çalışmada da kız çocukları henüz 14 yaşında ne bedensel, ne de ruhsal olarak hazır olmadıkları bir gebelik olgusuyla karşı karşıya kalmışlardır. Bu çocukları, uğradıkları cinsel istismarın yarattığı fiziksel ve ruhsal örselenmenin yanı sıra, gebeliğin ortaya çıkaracağı yeni fiziksel, ruhsal ve sosyal sorunlar beklemektedir. Dünyanın birçok ülkesinde yapılmış çalışmalarda da adölesan gebelikler ile çocukluk çağı istismarı arasında ilişki bulunduğuna dair güçlü kanıtlar elde edilmiştir $(16,17)$.

Çalışmamızda gebelikle sonuçlanan istismarı gerçekleştirenlerin $\% 56,8$ i çocuğun erkek arkadaşı ya da dini nikâhla evlendirildiği kocası, \%13,5’i ise aile üyeleridir. Ülkemizde yakın tarihli yapılan araştırmalarda istismarcının mağdurenin erkek arkadaşı olma sıklığ1 \%20-50, ensest sıklığ 
\%10-25 olarak bildirilmiştir (18-21). Çocukların çevresindeki dünyaya yönelik doğal ve yoğun merak duygusu, ilgi ve sevgi ihtiyaçları, erişkinler tarafından kolayca yönlendirilebilmeleri ve savunmasızlığı, büyümenin ve bağımsız olmanın doğal bir parçası olan olayı gizleme eğilimi çocuğu ideal mağdur yapmaktadır (19). Ancak kız çocukları erkeklere kıyasla sadece ülkemizde değil dünyanın birçok ülkesinde 1,5-3 kat daha fazla cinsel istismara uğramaktadır (22). Yulaf ve arkadaşlarının çalışmasında da kız mağdurların yaklaşık yarısının erkek arkadaşı tarafından, yarıdan fazlasının vajinal penetrasyon şeklinde ve \%49,4'ünün tekrarlayan şekilde cinsel istismara uğradığı bulunmuştur (23). Bizim çalışmamızda da kurbanların yarıya yakınında tehdit, hile, kandırma veya zorlama ile istismarın gerçekleştiği ve \%68,5’inde istismarın tekrarladığ1 görülmüştür. Yapılan lojistik regresyon analizinde hem tehdit ve kandırma varlığının, hem de tekrarlayan istismarın çocuklarda ruhsal patoloji varlığı için en büyük risk katsayısına sahip iki etken olduğu görülmüştür.

Ancak bu kadar erken yaşta gebe kalmak sadece beden ve ruh sağlığında değil, eğitim, geçim sıkıntısı gibi konularda da uzun süreli ve kalıcı etkiler taşımaktadır $(24,25)$. Nitekim çocukların yarısının gebeliği sırasında öğrenci olması ve bunların yaklaşık 2/3'sinin okulu terk etmesi sayılan olumsuz etkilere açık bir örnek teşkil etmektedir. Yapılan diğer çalışmalarda da erken evliliklerin mağdurlarının daha fazla kız çocukları olduğu ve erken yaş evliliklerinin daha çok kız çocuklarında okulu terk etmeye neden olduğu öne sürülmüştür (24-26). Toplumsal cinsiyetteki eşitsizliği derinleştiren bu olgu, kadınlar aleyhine bir olumsuz puana daha neden olurken, sosyal ve ekonomik açıdan da kocalarına biraz daha bağımlı hale getirmektedir.

Daha önce doğum yaptığ belirlenen kız çocuklarında ölü doğum ve erken doğum oranları Türkiye Nüfus ve Sağlık Araştırması 2013 yılı verilerinden 2-3 kat, gebeliğin istemli olarak sonlandırılmasının oranı ise aynı yaş grubundaki kız çocuklarından dokuz kat yüksektir (27). Uysal ve arkadaşlarının adölesan annelerle yaptığı çalışmada tıbbi abortus oranının \%18,3 olduğu belirtilmiş olup, bizim çalışmamızda da gebeliği doğum, düşük ya da istemli olarak sonlandırılmış çocuklarda bu oran benzer şekilde \%18,6 olarak bulunmuştur (28). Çalışmamızda canlı doğan çocukların \%4,9'unun annesinden ayrı çocuk yuvasında kurum bakımında olduğu, \%6,1’inin de evlat edindirildiği saptanmıştır. Adölesan dönemdeki kız çocuklarının üreme sitemi henüz olgunlaşmadığı için gebelik bu yaşlardaki kız çocuklarında çeşitli sağlık problemine hatta ölümlere neden olabilmektedir. Ayrıca bu gebeliklerde erken ve zor doğum riskinin de yüksek olduğu ve doğum sırasında ve sonrasında anne ve bebek ölüm ihtimalinin daha yüksek olduğu bildirilmektedir. İstenmeyen gebelikler henüz kendisi 'çocuk' olan bireyin bir de annelik sorumluluğunu üstlenmek zorunda kalmasına ve beraberinde birçok problem yaşamasına neden olmakta, çocuğun bakımsızlık sonucu ölme ihtimalini de yükseltmektedir (29).

Cinsel istismar sonucu gebe kalan kız çocuklarının \%50,4'ünde ruhsal patoloji geliştiği, tehdit/kandırma, tekrarlayan istismar ve ensest varlığının da istatistiksel anlamlılık gösteren risk faktörleri olduğu saptanmıştır. Ülkemizde yapılmış çalışmalarda cinsel istismara uğramış kız çocuklarının \%45-67'sinde ruhsal patoloji saptandı̆̆ belirtilmektedir $(15,21,23)$. Cinsel istismara maruz kalmış çocuklar için tanımlanmış özgül bir ruhsal hastalık tablosu olmamakla birlikte, saldırgan davranışlar, sosyal yalıtım, somatizasyon, anksiyete, depresyon, kâbuslar, uygunsuz cinsel davranışlar, alkol-madde kötüye kullanımı, yeme bozuklukları ve TSSB en sık bildirilen sorunlardır (30-33). Bu çalışmada ruhsal patoloji saptanan olguların \%91,1'inde depresyon, \%57,1'inde TSSB gibi yüksek oranlar bulunmasının iki ana sebebe bağlı olabileceği düşünülmüştür. Bunlardan ilki, ülkemizdeki çalışmaların çoğunda kız ve erkek olguların bir arada değerlendirilmiş olması ve yine literatürde sıkça vurgulandığı üzere erkek çocuklarında istismara bağlı ruhsal patolojik değişimlerin yakın dönemde güçlü ama izleyen dönemlerde giderek azalması nedeniyle düşük oranlar elde edilmesidir (34). İkinci neden ise çalışmamızdaki istismar kurbanlarının tamamının cinsel istismara maruz kalmış ve en az bir gebelik geçirmiş veya halen gebe olan kız çocuklarından oluşmasıdır. Maruz kalınmış cinsel istismara gebeliğin eklenmesinin hem fiziksel hem de ruhsal sağlığı daha olumsuz etkilediği birçok çalışmayla gösterilmiştir $(35,36)$

\section{Sonuç}

Cinsel istismar sonucu gebe kalmış çocukların yarısında ruhsal patoloji gelişiminin yanı sıra ülke ortalamasına kıyasla yüksek oranda ölü doğum ve düşük oranları saptanmıştır. Bu nedenle; ilk 48 en geç 72 saat içinde başvuran cinsel istismar mağdurlarında acil kontrasepsiyon uygulaması ile adölesan gebeliğin bütün olumsuz sonuçlarının oluşmadan önlenebileceği dikkate alınmalıdır. Akut dönemden sonra başvuran mağdurlarda ise gebelik olup olmadığının erken dönemde araştırılması, gebeliğin devamına ilişkin kararın bir an önce verilmesi, varolan gebeliklerin istem halinde uygun koşullarda sonlandırılması, olası riskler açısından adölesan annelerin gebelik izlemlerine önem verilmesi, erken yaşta doğum yapan bu çocuklar "güçsüz ebeveyn” olduklarından bu konuda sosyal destek sağlanması amacıyla gerekli yasal düzenlemelerin yapılması ve varolan ya da daha sonraki yaşantısında gelişebilecek ruhsal patolojilerin rehabilitasyonu için de izleme alınmasının önemli olduğu düşünülmüştür. 


\section{Kaynaklar}

1. Yılmaz E, Çelikel A, Değirmenci B, Zeren C, Gören S. Diyarbakır'da cinsel suç mağduru olguların değerlendirilmesi. Adli Tıp Bülteni 2011; 16(3): 93-103.

2. Balcı Y, Erbaş M, Işık Ş, Karbeyaz K. Muğla Adli Tıp Şube Müdürlüğ̈̈’ne başvuran cinsel saldırı olgularının değerlendirilmesi. Adli Tıp Bülteni 2014;19(2): 87-95.

3. Jewkes R, Sen P, Garcia-Moren C. Sexual violence. In: Krug EG, Dahlberg LL, Mercy JA, Zwi AB, Lozano R (eds). World report on violence and health. World Health Organization, Geneva, 2002:149-81.

(http://www.who.int/violence_injury_prevention/violence/wor ld_report/en/full_en.pdf) Erişim tarihi: 16.03.2015

4. Ovayolu N, Uçan Ö, Serindağ S. Çocuklarda Cinsel İstismar ve Etkileri. Fırat Sağlık Hizmetleri Dergisi 2007; 2(4): 13-22.

5. Köse S, Aslan Z, Başgül ŞS, Şahin S, Yılmaz Ş, Çıtak S, ve ark. Bir eğitim ve araştırma hastanesi çocuk psikiyatrisi polikliniğine yönlendirilen adli olgular. Anadolu Psikiyatri Dergisi 2011; 12: 221-5.

6. Guidelines for medico-legal care for victims of sexual violence, World Health Organization, Geneva, 2003: 75-93.

(http://whqlibdoc.who.int/publications/2004/924154628X.pdf) Erişim tarihi: 16.03 .2015

7. Maniglio R. The impact of child sexual abuse on health: a systematic review of reviews. Clin Psychol Rev 2009; 29(7): 64757.

8. Kendall-Tackett KA, Williams LM, Finkelhor D. Impact of sexual abuse on children: a review and synthesis of recent empirical studies. Psychol Bull 1993; 113(1): 164-80.

9. Holmes MM, Resnick HS, Kilpatrick DG, Best CL. Rape-related pregnancy: Estimates and descriptive characteristics from a national sample of women. Am J Obstet Gynecol 1996; 175(2): 320-5.

10. Kaufman J. Child abuse and neglect. In: Martin A, Volkmar FR, eds.Lewis's Child and Adolescent Psychiatry: A Comprehensive Textbook.4th ed. Philadelphia: Lippincott Williams \& Wilkins, 2007:693-9.

11. Bernet W. Çocuğa kötü muamele. Sadock BJ , VA Sadock VA, editörler.Kaplan\&Sadock's Comprehensive Textbook of Psychiatry (Türkçe), 8. Baskı. Çev. ed: Aydın H, Bozkurt A, Ankara: Güneş Kitabevi Ltd, 2007:3412-25.

12. Brahmbhatt $\mathrm{H}$, Kågesten $\mathrm{A}$, Emerson $\mathrm{M}$, Decker $\mathrm{MR}$, Olumide $\mathrm{AO}$, Ojengbede $\mathrm{O}$, et al. Prevalence and Determinants of Adolescent Pregnancy in Urban Disadvantaged Settings Across Five Cities. J Adolesc Health 2014; 55 (6,Supp): 48-57.

13. Ulibarri MD, Ulloa EC, Salazar M. Associations between Mental Health, Substance Use, and Sexual Abuse Experiences among Latinas. J Child Sex Abus 2015;24(1):35-54.

14. Warner LA, Alegria M, Canino G. Childhood maltreatment among Hispanic women in the United States: An examination of subgroup differences and impact on psychiatric disorder. Child Maltreat 2012; 17(2): 119-31.

15. Soylu N, Ayaz M. Adli değerlendirme için yönlendirilen küçük yaşta evlendirilmiş kız çocuklarının sosyodemografik özellikleri ve ruhsal değerlendirmesi. Anadolu Psikiyatri Dergisi 2013;14 (2): 136-44.

16. Pallitto C, Murillo V. Childhood Abuse as a Risk Factor for Adolescent Pregnancy in El Salvador. J Adolesc Health 2008; 42(6): 580-6.

17. Noll JG, Shenk CE, Putnam KT. Childhood Sexual Abuse and Adolescent Pregnancy: A Meta-analytic Update. J Pediatr Psychol 2009;34(4):366-78.
18. Gölge ZB, Yavuz MF, Yüksel Ş. Cinsel Saldırgan Profili. Adli Tıp Dergisi 2006; 20(1): 1-17.

19. İmren SG, Ayaz AB, Yusufoğlu C, Arman AR. Cinsel istismara uğrayan çocuk ve ergenlerde klinik özellikler ve intihar girişimi ile ilişkili risk etmenleri. Marmara Medical Journal 2013; 26:11-6.

20. Alpaslan AH. Çocukluk Döneminde Cinsel İstismar. Kocatepe Tip Dergisi 2014; 15(2): 194-201.

21. Aydin B, Akbas S, Turla A, Dundar C, Yuce M, Karabekiroglu K. Child sexual abuse in Turkey: an analysis of 1002 cases. J Forensic Sci 2015; 60(1):61-5.

22. UNFPA. Motherhood in childhood-facing the challenge of adolescent pregnancy. The State of World Population 2013.

(http://www.unfpa.org/sites/default/files/pub-pdf/ENSWOP2013-final.pdf) Erișim tarihi: 24.03.2015

23. Yulaf Y, Gümüștaș FÖ. Çocuk ve Ergenlerde Cinsel İstismarın Psikiyatrik Sonuçlarını Etkileyen Faktörler. Klinik Psikiyatri 2013; 16: 197-205.

24. Ayaz M, Ayaz AB, Soylu N. Cocuk ve Ergen Adli Olgularda Ruhsal Değerlendirme. Klinik Psikiyatri, 2012; 15: 33-40.

25. Mihçıokur S, Erbaş F, Akın A. Çocuk Gelinler ve Beklenen Olumsuz Sonuçları. Sağlık ve Toplum 2010; 20 (1):3-12.

26. Özcebe H, Ünalan T, Türkyılmaz S, Coşkun Y. Türkiye Gençlerde Cinsel Sağlık ve Üreme Sağlığı Araştırması, 2007; Ankara: Nüfus Bilim Derneği ve Birleşmiş Milletler Nüfus Fonu.

(http://www.nd.org.tr/custom/odesismc/Turkce_rapor.pdf) Erişim tarihi: 24.03 .2015

27. Hacettepe Üniversitesi Nüfus Etütleri Enstitüsü (2014), “2013 Türkiye Nüfus ve Sağlık Araştırması”. Hacettepe Üniversitesi Nüfus Etütleri Enstitüsü, T.C. Kalkınma Bakanlığı ve TÜBİTAK, Ankara, Türkiye.

(http://www.hips.hacettepe.edu.tr/TNSA_2013_ana_rapor.pdf) Erişim tarihi: 24.03.2015

28. Uysal C, Kir ZM, Goruk NY, Atli A, BezY, Gören S, et al. Being An Adolescent Mother. Acta Med Anatol 2014; 2 (1):14-8.

29. Malatyalı MK. Türkiye'de 'Çocuk Gelin' Sorunu. Nesne Psikoloji Dergisi 2014;2(3): 27-38.

30. Bernard-Bonnin AC, Hébert M, Daignault IV, Allard-Dansereau C. Disclosure of sexual abuse, and personal and familial factors as predictors of post-traumatic stress disorder symptoms in schoolaged girls. Paediatr Child Health 2008; 13(6): 479-86.

31. Fis NP, Arman A, Kalaca S, Berkem M. Psychiatric evaluation of sexual abuse cases: A clinical representative sample from Turkey. Child Youth Serv Rev 2010; 32: 1285-90.

32. Gölge ZB. Cinsel Travma sonrası oluşan ruhsal sorunlar. Nöropsikiyatri Arşivi. 2005; 42: 19-28.

33. Vural P, Uçar HN, Eray Ş, Çolpan M, Kocael Ö. Uludağ Üniversitesi Tip Fakültesi Hastanesi Çocuk Psikiyatrisi Polikliniğine Yönlendirilen Adli Olguların Sosyodemografik ve Klinik Özelliklerinin Değerlendirilmesi. Uludağ Üniversitesi Tıp Fakültesi Dergisi 2013; 39 (1): 49-53.

34. Godinet MT, Li F, Berg T. Early childhood maltreatment and trajectories of behavioral problems: Exploring gender and racial differences. Child Abuse Neg12014; 38 (3):544-56.

35. Lukasse M, Henriksen L, Vangen S, Schei B. Sexual violence and pregnancy-related physical symptoms. BMC Pregnancy Childbirth 2012; 12: 83.

36. Wosu AC, Gelaye B, Williams MA. Childhood sexual abuse and posttraumatic stress disorder among pregnant and postpartum women: review of the literature. Arch Womens Ment Health 2015; 18(1):61-72. 